\title{
Epidemiology of potentially inappropriate medication use in elderly patients in Japanese acute care hospitals.
}

\section{$\operatorname{AUTHOR}(S):$}

Sakuma, Mio; Morimoto, Takeshi; Matsui, Kunihiko; Seki, Susumu; Kuramoto, Nobuo; Toshiro, Jinichi; Murakami, Junji; ... Saito, Mayuko; Hiraide, Atsushi; Bates, David W

\section{CITATION:}

Sakuma, Mio ...[et al]. Epidemiology of potentially inappropriate medication use in elderly patients in Japanese acute care hospitals.. Pharmacoepidemiology and drug safety 2011 , 20(4): 386-392

\section{ISSUE DATE:}

2011-01-20

\section{URL:}

http://hdl.handle.net/2433/197139

\section{RIGHT:}

This is the peer reviewed version of the following article: Sakuma, M., Morimoto, T., Matsui, K., Seki, S., Kuramoto, N., Toshiro, J., Murakami, J., Fukui, T., Saito, M., Hiraide, A. and Bates, D. W. (2011), Epidemiology of potentially

in appropriate medication use in elderly patients in Japanese acute care hospitals. Pharmacoepidem. Drug Safe., 20: 386-392, which has been published in final form at http://dx.doi.org/10.1002/pds.2110; This is not the published version. Please cite only the published version.; この論文は出版社版でありません。引用の際には出版社版をご確認ご 利用ください。 
PDS-10-0156.R4

Original Report

\section{Epidemiology of Potentially Inappropriate Medication Use in Elderly Patients in Japanese Acute Care Hospitals}

Running head: Potentially Inappropriate Medication in Japan

Mio Sakuma, MD, MPH${ }^{1}$, Takeshi Morimoto, MD, $\mathrm{MPH}^{1}$, Kunihiko Matsui, MD, MPH${ }^{2}$, Susumu Seki, $\mathrm{MSc}^{1}$, Nobuo Kuramoto, $\mathrm{MD}^{1}$, Jinichi Toshiro, $\mathrm{MD}^{3}$, Junji Murakami, $\mathrm{MD}^{4}$, Tsuguya Fukui, MD, MPH${ }^{5}$, Mayuko Saito, MD, $\mathrm{MPH}^{5}$, Atsushi Hiraide, $\mathrm{MD}^{1}$ , and David W Bates, MD, MSc ${ }^{6}$

1 Center for Medical Education, Kyoto University Graduate School of Medicine, Kyoto, Japan

2 Department of General Medicine, Yamaguchi University Hospital, Ube, Japan

3 Rakuwakai Otowa Hospital, Kyoto, Japan

4 Aso lizuka Hospital, lizuka, Japan

5 St. Luke's International Hospital, Tokyo, Japan

6 Division of General Internal Medicine and Primary Care, Brigham and Women's Hospital and Harvard Medical School, Boston, MA

Author responsible for correspondence:

Takeshi Morimoto, MD, MPH

Center for Medical Education

Kyoto University Graduate School of Medicine

Konoe-cho, Yoshida, Sakyo-ku, Kyoto 606-8501, Japan

Telephone number: +81-75-751-4890

Fax number: +81-75-751-4250

E-mail address: morimoto@kuhp.kyoto-u.ac.jp

Keywords: Adverse drug events; epidemiology; geriatrics; inappropriate medication use; medication; patient safety

Take-home message

More than half of elderly inpatients were prescribed potentially inappropriate medications in Japanese acute care hospitals. 
Interception of such medication by healthcare providers was only $0.5 \%$.

Adverse drug events occurred $2.5 \%$ of those were actually administered.

This study was funded by grants 17689022 and 18659147 from the Ministry of Education, Culture, Sports, Science and Technology (MEXT) of Japan, and the Pfizer Health Research Foundation. These funding sources had no role in design and conduct of the study; collection, management, analysis, and interpretation of the data; and preparation, review, or approval of the manuscript.

All authors listed have contributed sufficiently to the project to be included as authors, and all those who are qualified to be authors are listed in the author byline. There was no potential conflict of interest other than description below: Dr. David Bates is on the clinical advisory board for Patient Safety Systems, which provides a set of approaches to help hospitals improve safety. Dr. Bates consults for Hearst, which develops knowledge resources. Dr. Bates serves on the clinical advisory board for SEA Medical Systems, which makes intravenous pump technology.

Word Count: 2,600 (Tables, 5; Figures, 1; References, 24), Abstract 248 
Purpose: The elderly receive many medications which may have adverse effects.

Little evidence is available about the epidemiology of potentially inappropriate medications being prescribed to the elderly in Japan as defined by the Beers criteria, or whether or not these medications result in harm when used in this population.

Methods: We conducted a prospective cohort study of patients aged $\geq 65$ years who were admitted to three acute care hospitals in Japan. Trained research nurses followed up patients from randomly selected wards and collected data about their medications and all potential adverse drug events (ADEs). Two independent reviewers evaluated all the data. The use of potentially inappropriate medications and their effects on patients were identified using the updated Beers criteria.

Results: A total of 2,155 elderly patients were eligible; $56.1 \%$ received at least one drug listed in the Beers criteria (BL drug). The rates of $B L$ drug prescriptions were 103.8 per 100 admissions and 53.7 per 1,000 patient-days, and the incidence rate of ADEs related to $B L$ drugs was 1.7 per $100 \mathrm{BL}$ drug prescriptions. Among patients aged $\geq 65$ years, relatively younger patients $(P=0.0002)$ and those with less complications $(P=0.04)$ were likely to be prescribed BL drugs.

Conclusions: Although BL drugs were frequently prescribed to elderly Japanese inpatients, the incidence of related ADEs appeared infrequent. These data suggest that re-evaluation of the appropriateness of the Beers criteria is needed before they 
are used in Japan and other nations to assess quality or for decision support. 


\section{Introduction}

Adverse drug events (ADEs) represent an important medical issue

because they result in 3-7 \% of all hospital admissions and they are associated with a substantial increase in morbidity and mortality. ${ }^{1-3}$ Elderly patients are particularly vulnerable to adverse drug events as they often have multiple comorbidities requiring treatment with drugs. Therefore, the quality of prescribed medications in this population, especially of potentially inappropriate medications, is a serious public health concern.

The explicit Beers criteria were developed in the U.S. by panels of expert geriatricians and pharmacologists in 1991 and they have been updated twice since. ${ }^{4-6}$ They include recommendations for avoiding medications with a high potential for harm and regarding alternatives with lower risk. Since Beers et al. initially published these criteria, they have received considerable attention and they have been widely used to evaluate the quality of medication prescribed to the elderly in various settings. ${ }^{7-14}$

No such criteria have been developed in Japan, but several Japanese physicians have applied the Beers criteria to avoid prescribing inappropriate medication even though their validity among the Japanese elderly has not been assessed. We believe that before widely applying the Beers criteria in Japan, it 
would be useful to evaluate the epidemiology of use of the drugs listed in the criteria (BL drugs) and furthermore to assess their effects on health among elderly Japanese, because other guidelines that have been developed outside Japan have not necessarily been applicable in Japan. ${ }^{15}$

We therefore scrutinized the epidemiology of BL drug prescriptions among elderly Japanese inpatients based on the cohort of the Japan Adverse Drug Events (JADE) study. We also investigated BL-related ADEs and the relationships between patients and doctors and BL drug prescriptions as factors.

\section{Methods}

\section{Study design and patient population}

The JADE study, a prospective cohort study, proceeded at three Japanese teaching hospitals with a total of 2,224 beds in 26 adult medical wards, 30 surgical wards, and three intensive care units (ICUs) other than obstetrics, gynecology and pediatric wards. ${ }^{16}$ Obstetrics, gynecology and pediatrics wards were excluded and all three ICUs were included because the JADE study was designed based on a previous study with a similar sample size. ${ }^{3}$ Fifty-six medical and surgical wards were stratified by ward type and hospital. The study wards were randomly selected within each stratum using a random number generator. Thus, we studied seven 
medical wards, eight surgical wards and three ICUs. The patients included in the JADE study were all adults aged $\geq 15$ years who were admitted to any of the 18 study wards during the period from January through June 2004 , and this study included patients aged $\geq 65$ years. The institutional review boards of three participating hospitals and Kyoto University Graduate School of Medicine approved the study.

\section{Data collection and classification}

The present report is limited to BL drug prescriptions in inpatients aged $\geq 65$ years. We used the updated Beers criteria that were initially developed in 1991 and updated twice to reflect newer evidence regarding the safety and efficacy of various medications. ${ }^{4-6}$ The updated Beers criteria divided inappropriate medication use in the elderly into two classes: 28 medications or classes of medications that are potentially inappropriate for the general elderly population and 35 drugs or categories of drugs that are inappropriate in persons with any one of 15 known medical conditions. ${ }^{6}$

The data collection method was based on that described in previous reports. $^{3,16,17}$ Investigators trained nurses and nursing students in the same manner and placed them in the participating hospitals where they reviewed practice data such as charts, laboratories, prescription data, reconciliations from pharmacies 
and incident reports, and assessed whether a BL drug was prescribed and if prescribed, its details including name, dosage, frequency, total number of prescriptions, instruction process, whether they were administered or intercepted and if intercepted, who was responsible. They also collected potential ADEs as well as all patients' characteristics. Comorbidity in the patients was quantified using the Charlson comorbidity index. ${ }^{18}$

Next, two independent physician reviewers evaluated all collected data and classified all potential ADEs as ADEs or excluded ADEs. When potential ADEs were related with $B L$ drugs, they were counted as the $B L$ drug-related $A D E s . \quad$ On the other hand, potential ADEs were excluded when considered to be non-BL drug-related. Furthermore, incidents were classified based on severity, which was categorized as fatal, life-threatening, serious and significant. ${ }^{17}$ Disagreements that affected classification of an event were resolved by the reviewers through discussion and consensus.

\section{Statistical analysis}

The units of analysis comprised patients and the number of BL drug prescriptions. The incidence of BL drug prescriptions per 1,000 patient-days and crude rates per 100 admissions were calculated. Furthermore, the rates of BL 
drug-related ADEs were also calculated by whether or not a prescription was actually administered.

Continuous variables are presented as means \pm standard deviation (SD)

or as medians with interquartile range; categorical variables are presented as numbers and ratios (\%). Relationships between patients' characteristic and BL drug use were assessed using a t-test or Wilcoxon rank sum test when a characteristic was a continuous variable and the $\mathrm{x}^{2}$ test when a characteristic was a categorical variable. The variables included were age category (5-year increments), gender, ward of admission (medical ward, surgical ward, ICU), whether the doctor in charge was a resident (trained for $<3$ years after obtaining a license), whether an operation was scheduled, the sum of prescription categories and the total number of complications upon admission.

\section{Results}

During the study period, 2,155 patients with 41,649 patient-days were enrolled (Figure 1). The mean (SD) age of these 2,155 patients was 76.9 (7.6) years and the most common ages were 75 to 79 (24.9\%) years followed by 70 to 74 (24.5\%) years (Table1). Slightly more men than women (53\% vs. $47 \%)$ were included and $48 \%, 40 \%$ and $13 \%$ of the patients were admitted to medical wards, 
surgical wards and ICUs, respectively.

Among these 2,155 patients, 1,209 (56.1\%) were prescribed at least one BL drug (Figure1): 550 (45.5\%), 396 (32.8\%) and 263 (21.8\%) patients filled their prescriptions for a single BL drug, for two drugs of concern and for three or more BL drugs, respectively.

A comparison of the 1,209 patients who were prescribed $B L$ drugs (BL group) with those who were not (946 patients, non BL group) showed that patient and physician characteristics were both associated with whether or not a patient received BL drug prescriptions (Table 1$)$. Relatively younger patients $(P=0.0002)$ and those with less complications $(P=0.04)$ were likely to receive $B L$ drug prescriptions. In particular, the risk of being prescribed BL drugs was lower among patients aged $\geq 80$ years than among those aged $<80$ years $(P<0.0001)$. The ratio of males to females did not significantly differ between the groups with and without BL. In terms of physician characteristics, attending physicians were more likely to prescribe BL drugs than residents $(P=0.02)$. Doctors in surgical wards prescribed $B L$ drugs more frequently than those in medical wards $(P<0.0001)$. In addition, patients who underwent surgery during hospitalization received more BL drug prescriptions than those who did not $(P<0.0001)$. The total number of categories of prescriptions that patients received on admission did not significantly differ between the BL and non BL 
groups.

A total of $2,237 \mathrm{BL}$ drugs were prescribed to these 1,209 patients

(Figure1). Thus, the rates of prescribed BL drugs were 103.8 per 100 admissions and 53.7 per 1000 patient-days. In terms of the details of prescribed BL drugs, only a few comprised the largest proportion of total prescriptions (Table 2). The prescribed frequencies of hydroxyzine (39.7\%), pentazocine (35.3\%), diazepam (9.5\%) and bisacodyl (6.4\%) were the highest (91\%) of all BL drugs and the prescribed median dosages of these drugs were $25,15,5$ and $10 \mathrm{mg}$, respectively (Table 2). Of these 2,237 BL drug prescriptions, 720 (32.2\%) were not administered to patients, $11(0.5 \%)$ were intercepted before being administered to patients by doctors or pharmacists, and the remaining 1,506 (67.3\%) were administered (Figure1). The 720 prescriptions were not intercepted but not actually taken by patients because such medications were prescribed for symptoms which did not happened to patients.

Among the 1,506 prescriptions that were administered to patients, we found that 37 ADEs occurred in 36 patients because one patient developed two events (Figure 1). Thus, the rates of ADEs caused by the BL drugs were 2.5 per 100 BL drug administrations and 1.7 per 100 BL drug prescriptions. These 37 ADEs were associated with $11 \mathrm{BL}$ drugs (Table 3). Diazepam accounted for nine (24.3\%) 
of all BL drug-related ADEs, and bisacodyl, hydroxyzine and pentazocine accounted for five (13.5\%) each (Table 3). Written orders for prescriptions were the most frequent (78.4\%) among BL drug-related ADEs and verbal order accounted for $16.2 \%$.

The most common category of symptoms associated with ADEs were central nervous system symptoms, which totaled 21 (56.8\%), followed by gastrointestinal symptoms (24.3\%) (Table 4). None of the patients died of an ADE. The five life-threatening ADEs (13.5\%) were respiratory failure $(n=2)$, loss of consciousness $(n=2)$ and hypotension $(n=1)$. All life-threatening cases were caused by diazepam except for hypotension by pentazocine. We also identified 22 (59.5\%) serious and $10(27.9 \%)$ significant ADEs.

\section{Discussion}

We found that patients over 65 years were frequently prescribed Beers List drugs in Japan, but the incidence of harm was quite low. Even among the adverse drug events which did occur, many were caused by diazepam, which should not be used in the elderly because there are a number of safer alternatives, and the rate for the remaining drugs was very low. These data suggest that the full Beers List may have limitations in Japan. 
Since Beers et al. published criteria for determining the appropriateness of medication in nursing home residents, the criteria have been applied to evaluate drugs prescribed to the elderly in various settings, including ambulatory care, ${ }^{12}$ outpatients, ${ }^{13}$ nursing homes, ${ }^{7,}, 14$ and community dwellings. ${ }^{8,10,11}$

Few studies have described BL drug prescriptions for inpatients (Table 5). ${ }^{19-22}$ Compared with these reports using different methodologies and in different populations, the rate of $\mathrm{BL}$ drug prescriptions in Japan seems higher than those reported in the U.S. and in European countries (Table5). There is no data on the incidence of ADEs due to BL drugs, and our study is the first report on inpatients setting. The incidence of the BL drug-related ADEs in Japan is relatively low considering high frequency of $B L$ drug prescriptions. These findings suggested that the frequent prescription of BL drugs has not been directly associated with an increasing incidence of ADEs among elderly Japanese inpatients on acute care hospitals. Whether or not the Beers criteria as a group are in fact helpful for avoiding the risk of ADEs among this population remains questionable.

Several factors might account for the low incidence of the BL drug-related ADEs in Japan. The prescribing behaviors of Japanese physicians identified in this study and the common dosages of each drug might be partial explanations. The common dosages of $\mathrm{BL}$ drugs prescribed in Japan and in the U.S. differed. The 
usual dose ranges of the most commonly prescribed BL drugs such as hydroxyzine, pentazocine, and diazepam in the U.S. are 50-100, 30-60, and 5-10mg, respectively, ${ }^{23}$ but these ranges are lower in Japan (Table 2 ). Thus, the application of lower dosages would protect against the occurrence of ADEs among elderly Japanese patients. Furthermore, such drugs are prescribed temporarily for some occasions such as premedication for operation or pain controls. Such temporal use of select BL drugs would also protect patients from the incidence of ADEs rather than long-term use of BL drugs in ambulatory settings.

The finding that relatively younger and healthier inpatients are more likely to be prescribed with $B L$ drugs suggests that physicians may already avoid prescribing them to frail elderly patients. The incidence of ADEs might increase if more BL drugs were administered to this group of patients.

We also found that BL drugs were more likely to be prescribed by attending physicians than residents, and by surgeons than internists. These prescribing behaviors would reflect the habit of prescribing custom drugs based on experience. Attending physicians habitually prescribe BL drugs without awareness of their risks, although better alternatives for the elderly are often available.

Surgeons also customarily prescribe certain specific types of BL drugs, such as pentazocine, which is one of the most frequently prescribed for pain, even though it 
had one of the highest frequencies of not being administered (in $41.3 \%$ of orders, it was not used). The main reason for this was simply that patients did not complain of pain. The high prevalence of these non-administered BL drug prescriptions (in $32.2 \%$ of all BL drug prescription, they were not used) could be partly because of such prescription behaviors among Japanese physicians, which means that many unnecessary medications could be ordered to elderly inpatients in Japan. This is a notable finding of the present study that warrants further investigation.

We tried to obtain generalizable data by using random select wards from three acute teaching hospitals, but the results should be different in other settings, such as nursing homes or outpatients. The low incidence of ADE related to BL drugs should be taken into account that the duration of medication use among inpatients on acute hospitals is relatively shorter than other settings. To scrutinize the safety profile of BL drugs, further research in different settings such as outpatients, nursing homes or community dwellings are needed in Japan as well as worldwide.

This study has several limitations. Bias might have decreased or increased the number of events identified because the selected units were aware of the study and actively involved in it. However, if anything the physicians in the units would have been likely to prescribe more conservatively than they would have otherwise. Our event identification system has another limitation in that we relied on 
record review and incident reports to find ADEs. Therefore, we would have missed ADEs that were not recorded in charts or reported to us. These factors might have led to an underestimation of ADE rates.

The present study has several advantages despite these limitations.

Since it was a prospective cohort study, events caused by BL drug prescriptions could be identified and detailed case assessments could be done, unlike in cross-sectional studies using national surveillance data. The study proceeded according to state-of-the-art methodology; ${ }^{3,17}$ thus, our rates should be comparable to other findings done using the same methodology. This should in turn facilitate assessment of differences in patient safety systems and health care management in various countries. Before applying criteria or guidelines developed in one country to another, strict and appropriate evaluation of such comparable data is essential. ${ }^{15}$ In the future, drugs will likely be ordered primarily through computerized physician order entry, and these applications can suggest both appropriate age-related dosages and avoiding certain medications which are truly high-risk in the elderly. ${ }^{24}$

In conclusion, BL drugs are frequently prescribed for elderly inpatients in Japan, whereas ADEs related to these drugs are infrequent, suggesting that commonly prescribed BL drugs have not been directly associated with increasing ADEs among this patient population. Furthermore, we found specific prescribing 
behaviors among Japanese physicians in particular with use of lower dosages, which may have decreased the risk of harm in elderly Japanese patients. Taking into account these findings, the most critical issue involved in improving "appropriate" prescription for the elderly appears to be the high prevalence of unnecessary medication rather than frequent use of BL drugs. Thus, further study and efforts to reduce unnecessary medication use are needed before applying the Beers criteria in Japan, especially as a tool for assessing the quality of prescribing across a population.

\section{Acknowledgments}

We are indebted to Ms. Makiko Ohtorii, Ms. Ai Mizutani, Ms. Kimiko Sakamoto, Ms. Eri Miyake, Ms. Takako Yamaguchi, Ms. Yoko Oe, Ms. Kyoko Sakaguchi, Ms. Kumiko Matsunaga, Ms. Yoko Ishida, Ms. Kiyoko Hongo, Ms. Masae Otani, Ms. Yasuko Ito, Ms. Ayumi Samejima, and Ms. Shinobu Tanaka for their assistance.

This study was funded by grants 17689022 and 18659147 from the Ministry of Education, Culture, Sports, Science and Technology (MEXT) of Japan, and the Pfizer Health Research Foundation. These funding sources had no role in design and conduct of the study; collection, management, analysis, and interpretation 
of the data; and preparation, review, or approval of the manuscript. 


\section{References}

1. Leape LL, Brennan TA, Laird N, et al. The nature of adverse events in hospitalized patients. Results of the Harvard Medical Practice Study II. N Engl J Med. 1991;324(6):377-384.

2. Brennan TA, Leape LL, Laird NM, et al. Incidence of adverse events and negligence in hospitalized patients. Results of the Harvard Medical Practice Study I. N Engl J Med. 1991;324(6):370-376.

3. Bates DW, Cullen DJ, Laird N, et al. Incidence of adverse drug events and potential adverse drug events. Implications for prevention. ADE Prevention Study Group. JAMA. 1995;274(1):29-34.

4. Beers MH, Ouslander JG, Rollingher I, Reuben DB, Brooks J, Beck JC. Explicit criteria for determining inappropriate medication use in nursing home residents. UCLA Division of Geriatric Medicine. Arch Intern Med. 1991;151(9):1825-1832.

5. Beers $\mathrm{MH}$. Explicit criteria for determining potentially inappropriate medication use by the elderly. An update. Arch Intern Med. 1997;157(14):1531-1536.

6. Fick DM, Cooper JW, Wade WE, Waller JL, Maclean JR, Beers MH. Updating the Beers criteria for potentially inappropriate medication use in older adults: results of a US consensus panel of experts. Arch Intern Med. 2003;163(22):2716-2724. 
7. Beers $\mathrm{MH}$, Ouslander JG, Fingold SF, et al. Inappropriate medication prescribing in skilled-nursing facilities. Ann Intern Med. 1992;117(8):684-689.

8. Stuck AE, Beers MH, Steiner A, Aronow HU, Rubenstein LZ, Beck JC.

Inappropriate medication use in community-residing older persons. Arch Intern Med. 1994;154(19):2195-2200.

9. Willcox SM, Himmelstein DU, Woolhandler S. Inappropriate drug prescribing for the community-dwelling elderly. JAMA. 1994;272(4):292-296.

10. Zhan C, Sangl J, Bierman AS, et al. Potentially inappropriate medication use in the community-dwelling elderly: findings from the 1996 Medical Expenditure Panel Survey. JAMA. 2001;286(22):2823-2829.

11. Hanlon JT, Fillenbaum GG, Kuchibhatla M, et al. Impact of inappropriate drug use on mortality and functional status in representative community dwelling elders. Med Care. 2002;40(2):166-176.

12. Goulding MR. Inappropriate medication prescribing for elderly ambulatory care patients. Arch Intern Med. 2004;164(3):305-312.

13. Curtis LH, Ostbye $\mathrm{T}$, Sendersky $\mathrm{V}$, et al. Inappropriate prescribing for elderly Americans in a large outpatient population. Arch Intern Med. 2004;164(15):1621-1625.

14. Fialova D, Topinkova E, Gambassi G, et al. Potentially inappropriate 
medication use among elderly home care patients in Europe. JAMA.

2005;293(11):1348-1358.

15. Morimoto T, Fukui T, Lee TH, Matsui K. Application of U.S. guidelines in other countries: aspirin for the primary prevention of cardiovascular events in Japan. Am J Med. 2004;117(7):459-468.

16. Morimoto T, Sakuma M, Matsui $\mathrm{K}$, et al. Incidence of Adverse Drug Events and Medication Errors in Japan: the JADE Study. J Gen Intern Med. 2010.

17. Morimoto T, Gandhi TK, Seger AC, Hsieh TC, Bates DW. Adverse drug events and medication errors: detection and classification methods. Qual Saf Health Care. 2004;13(4):306-314.

18. Charlson ME, Pompei P, Ales KL, MacKenzie CR. A new method of classifying prognostic comorbidity in longitudinal studies: development and validation. $J$ Chronic Dis. 1987;40(5):373-383.

19. Onder G, Landi F, Liperoti R, Fialova D, Gambassi G, Bernabei R. Impact of inappropriate drug use among hospitalized older adults. Eur J Clin Pharmacol. 2005;61(5-6):453-459.

20. Egger SS, Bachmann A, Hubmann N, Schlienger RG, Krahenbuhl S.

Prevalence of potentially inappropriate medication use in elderly patients:

comparison between general medical and geriatric wards. Drugs Aging. 
2006;23(10):823-837.

21. Rothberg MB, Pekow PS, Liu F, et al. Potentially inappropriate medication use in hospitalized elders. J Hosp Med. 2008;3(2):91-102.

22. Corsonello A, Pedone C, Lattanzio F, et al. Potentially inappropriate medications and functional decline in elderly hospitalized patients. J Am Geriatr Soc. 2009;57(6):1007-1014.

23. The Merck Manuals online medical library.

http://www.merck.com/mmpe/index.html. Accessed April 19, 2010.

24. Peterson JF, Kuperman GJ, Shek C, Patel M, Avorn J, Bates DW. Guided prescription of psychotropic medications for geriatric inpatients. Arch Intern Med. 2005;165(7):802-807. 
Table 1. Patients' backgrounds, and comparison between those prescribed with and without Beers drugs.

\begin{tabular}{|c|c|c|c|c|}
\hline Characteristics & $\begin{array}{l}\text { Total No (\%) } \\
(\mathrm{N}=2155)\end{array}$ & $\begin{array}{c}\text { BL drugs } \\
\text { No }(\%)(\mathrm{N}=1209)\end{array}$ & $\begin{array}{c}\text { Non BL drugs } \\
\text { No }(\%)(\mathrm{N}=946)\end{array}$ & $P$ value \\
\hline \multicolumn{5}{|l|}{ Age group (y) } \\
\hline $65-69$ & $383(17.8)$ & $226(18.7)$ & $157(16.6)$ & \multirow{6}{*}{0.0002} \\
\hline $70-74$ & $528(24.5)$ & $311(25.7)$ & $217(22.9)$ & \\
\hline $75-79$ & $537(24.9)$ & $325(26.9)$ & $212(22.4)$ & \\
\hline $80-84$ & $342(15.9)$ & $177(14.6)$ & $165(17.4)$ & \\
\hline $85-90$ & $223(10.4)$ & $108(8.9)$ & $115(12.2)$ & \\
\hline$\geq 90$ & $142(6.6)$ & $62(5.1)$ & $80(8.5)$ & \\
\hline Hospitalized days, median $(25,75 \%)$ & $11(5,22)$ & $13(6.5,28)$ & $9(3,17)$ & $<0.0001$ \\
\hline Sex (Male) & $1145(53.1)$ & $636(52.6)$ & $509(53.8)$ & 0.6 \\
\hline Race (Asian; Japanese) & $2141(99)$ & $1202(99.4)$ & $939(99.3)$ & 0.6 \\
\hline \multicolumn{5}{|l|}{ Ward } \\
\hline Surgical & $854(39.6)$ & $590(44.8)$ & $264(27.9)$ & \multirow{3}{*}{$<0.0001$} \\
\hline Medical & $1025(47.6)$ & $479(39.6)$ & $546(57.7)$ & \\
\hline ICUs & $276(12.8)$ & $140(11.6)$ & $136(14.4)$ & \\
\hline Doctor in charge (Resident) & $600(27.8)$ & $313(25.9)$ & $287(30.3)$ & 0.02 \\
\hline Surgery (Scheduled) & $511(23.7)$ & $413(34.2)$ & $98(10.4)$ & $<0.0001$ \\
\hline $\begin{array}{l}\text { Total number of categories of } \\
\text { prescription on admission, median } \\
(25,75 \%)\end{array}$ & $4(3,6)$ & $4(2.5,6)$ & $4(3,6)$ & 0.4 \\
\hline Charlson comorbidity index, median & $3(1,5)$ & $3(1,5)$ & $3(1,5)$ & 0.04 \\
\hline
\end{tabular}


$\mathrm{BL}$, Beers listed in the Beers criteria; ADE, adverse drug event; ICU, intensive care unit. 
Table2. Details of Beers drugs prescribed during the study period.

\begin{tabular}{|c|c|c|c|c|c|c|}
\hline Beers drugs & $\begin{array}{c}\text { Total } \\
\text { prescriptions }\end{array}$ & $\begin{array}{c}\text { Dose/day } \\
\text { median( quartile) }\end{array}$ & Mean (SD) & Administered & Intercepted (\%) & $\begin{array}{c}\text { Not administered } \\
\text { because of } \\
\text { unnecessary (\%) }\end{array}$ \\
\hline Hydroxyzine & 888 & $25(25,25)$ & $28.4(12.2)$ & 599 & $7(0.8)$ & 282 (31.8) \\
\hline Pentazocine & 789 & $15(15,15)$ & $16.8(14.6)$ & 463 & $0(0)$ & $326(41.3)$ \\
\hline Diazepam & 213 & $5(5,5)$ & $6.3(6.3)$ & 146 & $1(0.5)$ & $66(31.0)$ \\
\hline Bisacodyl & 144 & $10(10,10)$ & $10.5(2.8)$ & 118 & $2(1.4)$ & $24(16.7)$ \\
\hline Ticlopidine & 40 & $200(200,200)$ & $187.5(60.7)$ & 40 & $0(0)$ & $0(0)$ \\
\hline Nifedipine & 40 & $5(5,5)$ & $5(0)$ & 23 & $0(0)$ & $17(42.5)$ \\
\hline Chlorpheniramine & 35 & $6(4,10)$ & $7.1(3.6)$ & 32 & $0(0)$ & $3(8.6)$ \\
\hline Disopyramide & 20 & $125(50,300)$ & 162.5 (111.1) & 19 & $0(0)$ & $1(5.0)$ \\
\hline Doxazosin & 16 & $1(1,2)$ & $1.6(1.0)$ & 16 & $0(0)$ & $0(0)$ \\
\hline Cimetidine & 15 & $400(200,400)$ & $373.3(148.6)$ & 15 & $0(0)$ & $0(0)$ \\
\hline Pentobarbital & 11 & $50(25,50)$ & $263.8(741.8)$ & 11 & $0(0)$ & $0(0)$ \\
\hline Triazolam & 8 & $0.5(0.5,0.5)$ & $0.56(0.18)$ & 7 & $1(12.5)$ & $0(0)$ \\
\hline Amitriptyline & 6 & $25(10,42.5)$ & $30(26.1)$ & 5 & $0(0)$ & $1(16.7)$ \\
\hline Diphenhydramine & 4 & $50(50,50)$ & $50(0)$ & 4 & $0(0)$ & $0(0)$ \\
\hline Indomethacin & 2 & $25(25,25)$ & $25(0)$ & 2 & $0(0)$ & $0(0)$ \\
\hline Naproxen & 2 & $450(300,600)$ & $450(212.1)$ & 2 & $0(0)$ & $0(0)$ \\
\hline Amiodarone & 1 & $250(250,250)$ & $250(-)$ & 1 & $0(0)$ & $0(0)$ \\
\hline Cyproheptadine & 1 & $12(12,12)$ & $12(-)$ & 1 & $0(0)$ & $0(0)$ \\
\hline
\end{tabular}




\begin{tabular}{|c|c|c|c|c|c|c|}
\hline Thioridazine & 1 & $30(30,30)$ & $30(-)$ & 1 & $0(0)$ & $0(0)$ \\
\hline Thyroid & 1 & $100(100,100)$ & $100(-)$ & 1 & $0(0)$ & $0(0)$ \\
\hline
\end{tabular}


Table3. Summary of Beers drugs causing adverse drug events.

\begin{tabular}{lccc}
\hline \multicolumn{1}{c}{ BL drug } & Administered & Number of ADEs & $\begin{array}{c}\text { Rate } \\
\text { (ADE / Administered) }\end{array}$ \\
\hline Hydroxyzine & 599 & 5 & 0.8 \\
Pentazocine & 463 & 5 & 1.1 \\
Diazepam & 146 & 9 & 6.2 \\
Bisacodyl & 118 & 5 & 4.2 \\
Ticlopidine & 40 & 3 & 7.5 \\
Chlorpheniramine & 32 & 1 & 3.1 \\
Nifedipine & 23 & 1 & 4.3 \\
Doxazosin & 16 & 4 & 25.0 \\
Cimetidine & 15 & 1 & 6.7 \\
Amitriptyline & 5 & 2 & 40.0 \\
Thioridazine & 1 & 1 & 100.0 \\
\hline
\end{tabular}

$\mathrm{BL}$, drugs listed in the Beers criteria; ADE, adverse drug event. 
Table4. Types of adverse drug events.

\begin{tabular}{cc}
\hline Type of ADE & Total \\
\hline Bleeding & 2 \\
Central nervous system & 21 \\
Allergic reaction & 1 \\
Liver disorder & 2 \\
Cardiovascular & 1 \\
Gastrointestinal & 9 \\
Respiratory & 1 \\
Total & 37 \\
\hline
\end{tabular}

ADE, adverse drug event. 
Table5. Comparison of the rate of Beers drug prescriptions and adverse drug events

\begin{tabular}{|c|c|c|c|c|c|}
\hline Study & JADE study & Onder G & Egger S & Rothberg M & Corsonello A \\
\hline Country & Japan & Italy & Switzerland & U.S. & Italy \\
\hline Setting & $\begin{array}{l}3 \text { acute } \\
\text { teaching } \\
\text { hospitals }\end{array}$ & $\begin{array}{c}\text { Community and } \\
\text { university } \\
\text { hospitals }\end{array}$ & $\begin{array}{l}1 \text { teaching } \\
\text { hospital }\end{array}$ & $\begin{array}{l}384 \text { small- to } \\
\text { medium- sized } \\
\text { non-teaching } \\
\text { hospitals }\end{array}$ & $\begin{array}{c}\text { Community and } \\
\text { university } \\
\text { hospitals }\end{array}$ \\
\hline Wards & $\begin{array}{l}7 \text { medical wards } \\
\text { / } 8 \text { surgical } \\
\text { wards / } 3 \text { ICUs }\end{array}$ & $\begin{array}{l}81 \text { geriatric and } \\
\text { internal } \\
\text { medicine wards }\end{array}$ & $\begin{array}{c}1 \text { general } \\
\text { medical ward / } 1 \\
\text { geriatric ward }\end{array}$ & $\begin{array}{c}\text { Patients with } 7 \\
\text { selected } \\
\text { diagnoses on all } \\
\text { wards }\end{array}$ & $\begin{array}{c}11 \text { acute care } \\
\text { medical wards / } \\
3 \text { long-term } \\
\text { care and } \\
\text { rehabilitation } \\
\text { units }\end{array}$ \\
\hline Number of patients & 2,155 & 5,152 & 800 & 493,971 & 506 \\
\hline Data acquisition method & Reviewers & Reviewers & Database & Database & Reviewers \\
\hline $\begin{array}{l}\text { No of patients receiving BL drug } \\
\text { / } 100 \text { patients }\end{array}$ & 56.1 & 28.6 & $\begin{array}{l}16.0 \text { (medical } \\
\text { ward) / } 20.8 \\
\text { (geriatric ward) }\end{array}$ & 49 & 20.6 \\
\hline $\begin{array}{l}\text { No of BL drug-related ADEs / } \\
100 \mathrm{BL} \text { drug administrations }\end{array}$ & 2.5 & Not available & Not available & Not available & Not available \\
\hline
\end{tabular}


$B L$, Beers listed in the Beers criteria; ADE, adverse drug event; ICU, intensive care unit. 
Figure legend

Figure 1. Flowchart of patients

Figure 1

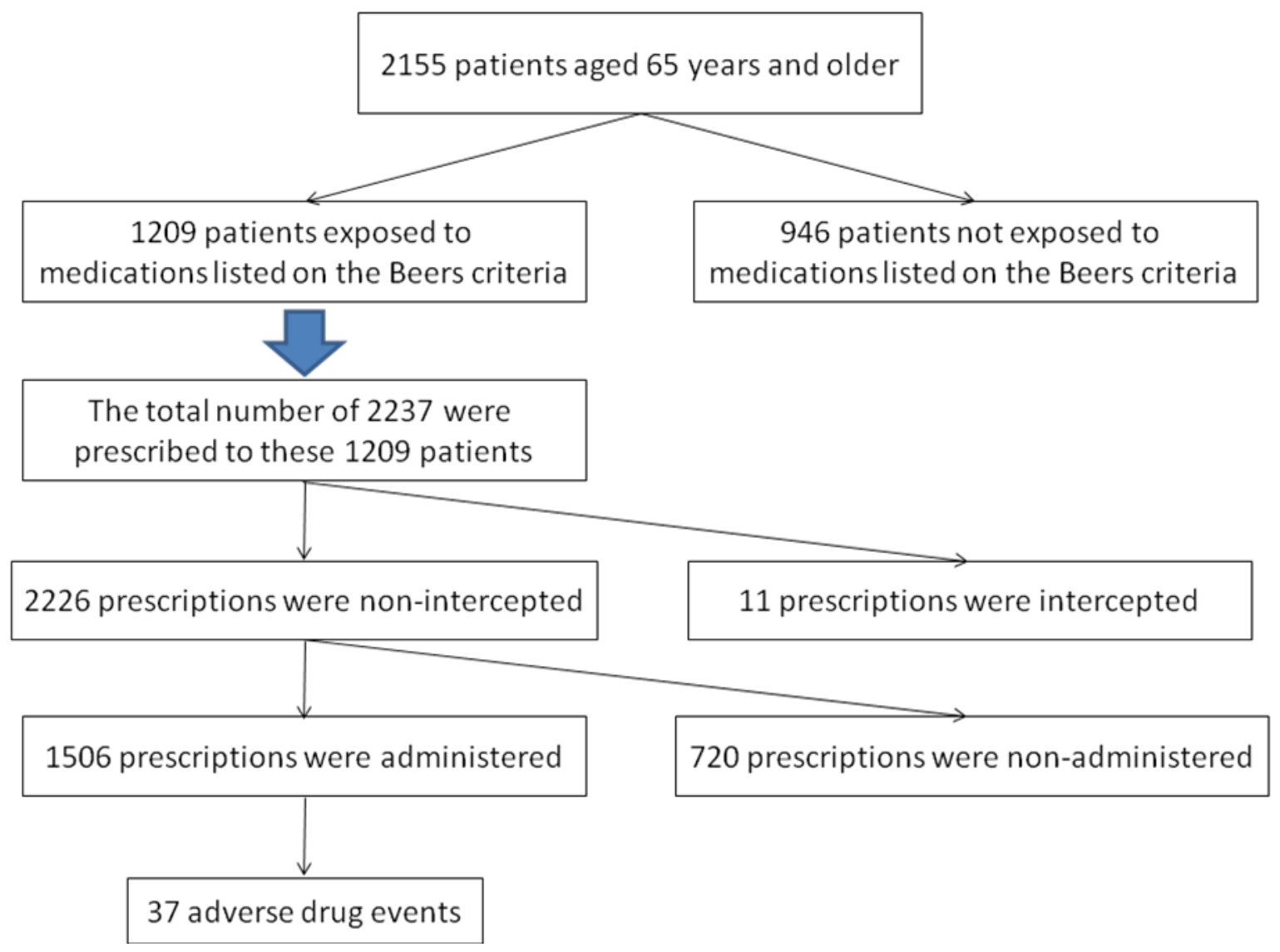

